\title{
De socialidades, Susanas y distanciamientos: contrastan- do eslóganes para el cuidado durante la pandemia de la COVID-19
}

\section{Miguel Angel Sahagún Padilla ${ }^{1}$}

\section{Resumen}

La reorganización de la vida social durante la pandemia de la COVID-19 no supone una ruptura en la organización del mundo; más bien agudiza algunos de sus rasgos y tendencias. En este ensayo interpretativo, examino dos frases cortas que han funcionado como parte de los eslóganes en las campañas para reducir los contagios del virus SARS-CoV2: social distancing y Susana Distancia. Contrastanto las frases en términos de

1 Universidad Autónoma de Aguascalientes, miguel.sahagun@edu.uaa.mx 
sus propiedades formales y de las imágenes que nos evocan, discuto sus implicaciones y las condiciones que les dan sentido. Mientras que social distancing puede entenderse como acción abstracta y prescriptora bajo la imagen de un círculo o esfera, Susana Distancia aparece como sustantivo particularizado, agente y cuerpo que cuida y separa.

Palabras clave: imágenes; discurso; eslóganes; COVID19; pandemia.

\section{Abstract}

The reorganization of social life during the COVID-19 pandemic does not imply a break in the organization of the world; rather it sharpens some of its traits and tendencies. In this interpretive essay, I examine two short phrases that have worked as part of the slogans in campaigns to reduce the spread of the SARS-CoV2 virus: social distancing and Susana Distancia. I contrast the sentences in terms of their formal properties and the images that they evoke, I discuss their implications and the conditions that give them meaning. While social distancing can be understood as an abstract and prescriptive action under the image of a circle or sphere, Susana Distancia appears as a particularized noun, agent and body that provides care and separates.

Keywords: images; discourse; slogans; COVID-19; pandemic. 
Social distancing no es lo mismo que Susana Distan$\mathrm{cia}^{2}$. Las frases podrán estar emparentadas, pero no son lo mismo. Mi argumento es que esas diferencias son informativas de la organización de subjetividad y cultura en al menos algunas esferas de nuestro vivir en común. Estoy hablando de las frases que hemos escuchado insistentemente desde que comenzó la respuesta a la pandemia. Como sea, quiero sugerir algunas reflexiones sobre estas dos frases cortas. Quiero pensar además sobre los términos que las componen; preguntarme a qué nos suenan esos términos y preguntarme además a qué podrían sonarnos en otras circunstancias. Finalmente, me gustaría entrar en la cuestión de las imágenes que las dos expresiones evocan: qué es lo que nos imaginamos cuando escuchamos social distancing y Susana Distancia. Debo decir además que estoy convencido de que, de algún modo, llegaremos a cuestiones complejas y aparentemente alejadas del tema como las clases sociales, los afectos y el deseo.

En cuanto a la elección de estas dos frases, social distancing y Susana Distancia, alguien podría acusarme de partir de una elección arbitraria. Intentado ser breve, miraría a los ojos a mi hipotético acusador y le diría que sí, que la elección es arbitraria en el sentido de que podría haber otras elecciones, pero que quizá

2 Este texto fue preparado como parte de la charla "Amor en tiempos de la COVID", realizado en la Universidad Cuauhtémoc de Aguascalientes el 12 de septiembre de 2020. 
sea menos arbitraria -o más pertinente- que esas otras elecciones posibles si consideramos el interés de entender cómo vamos intentando acomodarnos a lo que pasa con la pandemia y qué nos dicen los intentos de responder a la pandemia sobre nuestras formas de relacionarnos.

Iba a poner como ejemplo de la selección de una expresión arbitraria la palabra calentura, pero luego pensé que también podría ser interesante, porque se usa tanto en relación con la enfermedad COVID-19 como con respecto a los asuntos amorosos, que a veces pareciera que también son una enfermedad. Pero estoy divagando. La elección de estas dos frases responde a la búsqueda de un par de puntos clave; nodos o ubicaciones en estas redes de sentidos, sinsentidos y sobresentidos que empleamos para navegar la pandemia. La sonoridad de estas dos frases es la materialidad específica de eso simbólico que nos da entrada a lo que habría entre nuestras relaciones y la COVID-19. Me parece que es difícil oponerse a la idea de que ambas frases son claramente reconocibles en ese sentido.

Otro señalamiento posible es que lo lógico sería emparejar —un verbo muy amoroso- distanciamiento social a social distancing y, en sentido estricto, pasando por alto el contexto, el señalamiento sería correcto. Pero no creo que sea buena idea ignorar el contexto. Lo cierto es que en México la referencia que se ha desbordado en su momento ha sido la frase Susana Distancia más que la de distanciamiento social. 
Me parece importante señalar que la expresión social distancing se ha empleado de varias maneras en la era previa a la pandemia de la COVID-19. Un empleo de la frase, que prácticamente va en el mismo sentido que durante la pandemia, lo encontramos en relación con otros agentes infecciosos (e.g., Targeted Social distancing designs for pandemic influenza, de Glass et al., 2006). Pero hay otros usos que resultan, como mínimo, dignos de mención, ya que tienen que ver con cuestiones de poder, exclusión y discriminación (e.g., Keeping directors in line: Social distancing as a control mechanism in the corporate elite, de Westphal y Khanna, 2003; o Avoiding stigma by association: subtle prejudice against lesbians in the form of social distancing, de Swim, Ferguson y Hyers, 1999). Social distancing se relaciona entonces con cuestiones de odio, poder y muerte, eso que está en el reverso del cuidado y que, por alguna razón no difícil de anticipar, me lleva a pensar en la serie Game of Thrones.

Evidentemente, estas usos previos no los vamos a encontrar - por lo menos no de esta forma - con la expresión Susana Distancia. Sabemos que se trata de una frase de reciente creación como parte de las medidas propuestas por el gobierno federal de México para frenar la pandemia. Así, esta frase está mucho más vinculada a unos tiempos y lugares institucionales en particular que la de social distancing.

Paso ahora a centrarme en la literalidad de las expresiones. No estoy convencido de que este ejercicio 
sea muy ortodoxo, ya que se trata de expresiones en diferentes idiomas. Como sea, presentaré mis observaciones, preguntas y reflexiones al respecto. Solo después juzgaré la pertinencia del ejercicio. ¿Qué voy a hacer? Para examinar las frases en su literalidad, procederé por medio de una serie de contrastes. Veamos a dónde podemos llegar con esta estrategia.

\section{Primer contraste}

Social distancing es una actividad. Distancing es gerundio. No es distance, sino distancing. Es difícil traducir al español sin sustantivar la expresión. El traductor de Google arroja "distanciamiento social" como resultado. Como se trata de un gerundio, no solo nos remite a actividad, sino a una actividad que está en curso, que va desarrollándose. Por su parte, en Susana Distancia no hay verbo, hay cosa: la distancia.

Pero el inglés es un poco tramposo, porque aunque se trate de un verbo en gerundio acompañado de un adjetivo, la expresión como un todo funciona además como cosa. Como sea, tiene más sentido decir "We should practice some Social distancing" que decir "deberíamos practicar un poco de Susana Distancia". En español siempre quedará mejor hablar de practicar "la" sana distancia, aunque me parece que ahora nos resultaría imposible no pensar en Susana.

Así, el primer contraste nos remite a la diferencia entre una actividad y una cosa 


\section{Segundo contraste}

En la expresión social distancing, el verbo sustantivado distancing recibe el adjetivo social. Distanciando socialmente: distanciándonos, distanciándome, distan-ciándote, distanciándoles. La persona queda indefinida, pero así es el inglés. Hay una actividad, un hacer más o menos cosificado que viene acompañado por un modo. Por un lado, podríamos preguntarnos qué implica que la actividad se plantee en términos de distanciar y no de alejar o separar. Creo que esto guarda una estrecha relación con la ambigüedad de la persona. No queda claro qué o quién es el agente del distanciamiento, a menos que -esto me parece particularmente relevante- lo social sea el agente y se disfrace de adjetivo. Así, no hablaríamos entonces de un distanciamiento que es de tipo social, sino de que lo social -lo que sea que esto signifique- estaría haciendo ese distanciamiento. Lo social es lo que distancia. Lo cual podría parecer un contrasentido ya que al pensar en, por ejemplo, lo social en oposición a lo asocial, tenderíamos a pensar en gente junta versus gente separada o sola. Pero esta tema pertenece al mundo de las imágenes, así que debería evitar adelantarme.

Con Susana Distancia las diferencias son notables. Lo que tenemos es un nombre propio. Por supuesto que es un juego de palabras. Ahí está la gracia de la propuesta, la naturaleza promocional de la frase. 
Si nos la tomamos en serio $-\mathrm{y}$ cuando hacemos este tipo de análisis es justo la forma en que debemos proceder-, notaremos que el apellido sería Distancia y el nombre de pila Susana. El apellido es, de algún modo, lo que viene dado, la familia. Habría muchos y muchas Distancia, como hay muchos y muchas López o Pérez, pero Susana, sólo una. Bueno, no nece-sariamente, podría haber varias, pero el nombre de pila no deja de particularizar la categoría más amplia del apellido. Como sea, el apellido nos viene dado y el nombre lo eligen por nosotros. Además, si atendemos a la homofonía de Susana, que sería "su sana", es decir, "su", espacio, "sana", lo que nos queda es: (1) un pronombre posesivo, su, que podría referirse a la tercera persona del singular o a la segunda persona del singular sin tuteo; y (2) lo que podría ser el adjetivo de un sustantivo femenino, sana, o un verbo que podría entenderse como conjugado en presente simple, descripción, o como imperativo, prescripción.

Considerando lo anterior, el segundo contraste es entonces entre eso que llamamos lo social, que va separando —actividad-, y una distancia — cosa- que sea sana para el otro o en sí misma.

\section{Tercer contraste}

Social distancing es, entre otras cosas, un concepto. $Y$ como concepto, presenta un grado de abstracción, una 
característica o propiedad que se observa en -y distingue de- determinados objetos y en sus relacio-nes. Dado que el modo de la propiedad descrita recae en la palabra social, es difícil no preguntarse por qué el distanciamiento es social y no físico. Siendo estrictos, lo que se estaría señalando es una separación física, más que social, a no ser que la noción de social —que, por cierto, no sabemos cuál sea- tenga un carácter marcadamente mecanicista.

Por otra parte, Susana Distancia es una concreción, un nombre propio, como Pancho Villa, Felipe Calderón o Clark Kent. Pero a diferencia de estos, es un nombre de mujer. Podría ser un accidente, ya que se traba de convertir en nombre la expresión previa, sana distancia. Por otra parte, Susano Distanciamiento no suena bien, además de que se prestaría a oscuros juegos de doble sentido. Como sea, se trata de un nombre propio y de mujer. Pero este nombre propio quiere funcionar como estampa del concepto sana distancia.

Así, el tercer contraste es entre abstracción y concreción, entre un concepto y una estampa. Pero aún no es el momento de hablar de imágenes.

\section{Cuarto contraste}

El concepto social distancing, que remite a una característica o propiedad aplicable a personas en relación, es, además de una descripción, una prescrip-ción. Es difícil pensar en esta última sin atender al contexto de uso de 
la expresión, pero es que es justamente ahí donde cobra su sentido: social distan-cing establece un criterio al cual habría que aproxi-marse en las formas de interactuar con el otro.

Susana Distancia no es prescripción, al menos no en la misma forma en que social distancing lo es. Susana Distancia es alegoría de la prescripción. Y aquí me cuesta no recordar esas tensiones entre católicos y protestantes en torno al uso de imágenes y figuras religiosas; al riesgo de terminar practicando alguna forma de idolatría. Adorar la imagen sería una forma de perder de vista el deber ser, la prescripción. Susana Distancia, en tanto que alegoría de algo más, es pegajosa y de fácil comprensión, pero supone añadir un paso más, una instancia mediadora entre la prescripción y el sujeto que debería seguirla.

El cuarto contraste es pues entre una prescripción disfrazada de descripción y una alegoría.

\section{Concluir con tres imágenes y una ausencia}

A modo de cierre, abordaré la cuestión de las imágenes. El tema de las imágenes es más complejo, porque la relación entre código e imagen es múltiple y variable de sujeto a sujeto. No hay univocidad. Pero a pesar de lo complejo del asunto, no me atrevería a pasarlo por alto. Hay tres imágenes que se relacionan de diferente forma con las dos frases que hemos revisado: la línea, el círculo y la señora/superheroína. 
Social distancing es, imaginariamente, una línea, un radio ideal que establece circunferencias alrededor de puntos que representan cuerpos. La concreción de esta imagen la encontramos en memes y vídeos de personas que caminan con un círculo de, por ejemplo, alambre, sujeto de forma equidistante con sus cuerpos como eje y que delimita el espacio que no debería ser invadido por otros.

What we can learn from looking at the application of these different measures across a range of diseases that stir fear and often panic is that these remarkable displays of community or government authority-sometimes heavy-handed but typically widely socially accepted-were not equal in the ways they treated groups within society. So often diseases turn us against "the other," blaming countries and even particular ethnic communities. (Fairchild, Gostin \& Bayer, 2020)

Y si hablamos de amor en su sentido más habitual, el ser amado debería se aquel que, al menos en nuestro deseo, se ubicaría dentro del imaginario círculo; aquel con el que, al menos a ratos, se cohabita. De algún modo, la práctica del social distancing es una especie de geometría que separa los otros cuerpos, los cuerpos que no son mi cuerpo, en dos grupos. Primero, un gran grupo, uno que prácticamente tiende a infinito, de cuerpos cuya presencia no se desearía más acá del social distancing. Luego estaría ese otro grupo, muy reducido - no llegaría a las dos cifras-, de cuerpos que 
me gustarían, al menos a ratos, de este lado de la imaginaria línea divisoria. $\mathrm{Y}$ desde luego, la expectativa $\mathrm{o}$ el deseo no coinciden del todo con la práctica, pero inevitablemente se relacionan con ella. Amarte es desear que estés de este lado, odiarte es desear que te mantengas del otro lado. El miedo es el filtro que permea la visión, que determina a quién quiero cerca y a quién no. Pero el miedo no determina que yo pueda, para todos los efectos, elegir. Una persona tiene poder en la medida en que puede definir quiénes están más acá y más allá de la línea y carece de poder en la medida en no puede decidir quiénes están más acá y más allá. Todo este universo de afectos, deseos y organiza-ciones precede a la pandemia, por supuesto, y supera a la expresión social distancing, pero se radicaliza cuando la pandemia en general y las consignas como esta entran en juego. Así, lo que vemos es que se agudizan las diferencias de poder: quienes de por sí no pueden decidir quiénes están más acá y más allá ven recortados sus escasos márgenes de maniobra. Que nos quede claro: el aumento de la violencia doméstica, machista durante la pandemia (Bradbury-Jones y Isham, 2020; Usher et al., 2020) no se debe al aislamiento, sino a diferencias de poder.

Pero volviendo a las imágenes, la línea, este radio del que hablamos, se establece imaginariamente entre dos cuerpos. Iba a decir personas, pero la imagen es la de dos cuerpos. Y la línea, propiedad unidimensional, tiene que medir al menos dos metros. $\mathrm{O}$ seis pies en el 
sistema imperial. El amor que se siembra aquí es el amor al cálculo y a los dispositivos que lo acompañan; a las cruces, líneas o círculos en el suelo que funcionan como referencia para erigir esa línea cuando vamos al mundo a comprar pan o parecetamol. Nos hemos de imaginar un mundo que incluye en su realización cotidiana una gran cantidad de líneas imaginarias que, imaginariamente, miden dos metros, o seis pies, y que vamos trazando entre cuerpos, el propio y los ajenos.

En México hemos hecho las cosas de otra manera. Para resistirnos a pensar en rayas, hemos pensado en una señora-superheroína. Imaginaria-mente, parece que Susana Distancia es una madre que nos cuida de la enfermedad. Así, si nos cuidamos es, en parte al menos, porque es lo que mamá desea. Por supuesto que la línea sigue ahí, del dedo corazón izquierdo al dedo corazón derecho de la señora/madre/superheroína. Amor, la imagen en el centro del vacío que hay que dejar en el trato con los otros, líneas y círculos, brazos, dedos, toda esta imaginería me lleva a consideraciones que colindan con el campo de lo freudiano-lacaniano y que no estoy en condiciones de abordar.

Hasta ahora, el gran ausente en este discurrir es el virus. El actante, generador de miedo; el protagonista que irrumpe; Invisible, etéreo, ubicuo; portentoso y parasitario. Aunque sabemos que la probabilidad de que comparta oración o párrafo con cualquiera de las dos frases que hemos estado revisando es enorme, en sí mismo no es recogido en las frases. 
Me gustaría que lo que quede en el lector de este ejercicio - un ejercicio de libre discurrir, abierto, sin cierre ni afirmación rotunda- sirviera sobre todo para hacernos preguntas sobre nuestras vidas en común y sobre lo que aflora con un evento como la pandemia, sobre la agudización de las desigualdades y sobre los velos que intentamos correr sobre ellas.

\section{Referencias}

Bradbury-Jones, C. y Isham, L. (2020). The pandemic paradox: The consequences of COVID-19 on domestic violence. Journal of clinical nursing, 29(1314), 2047-2049. doi:10.1111/jocn.15296

Fairchild, A., Gostin, L. y Bayer, R. (2020). Vexing, Veiled, and Inequitable: Social Distancing and the "Rights" Divide in the Age of COVID-19. The American journal of bioethics: AJOB, 20(7), 55-61. doi:10.1080/15265161.2020.1764142

Glass, R. J., Glass, L. M., Beyeler, W. E. y Min, H. J. (2006). Targeted social distancing design for pandemic influenza. Emerging infectious diseases, 12(11), 1671-1681. doi:10.3201/eid1211.060255

Swim, J. K., Ferguson, M. J. y Hyers, L. L. (1999). Avoiding Stigma by Association: Subtle Prejudice Against Lesbians in the Form of Social Distancing. Basic and Applied Social Psychology, 21(1), 6168. doi:10.1207/s15324834basp2101_6 
Usher, K., Bhullar, N., Durkin, J., Gyamfi, N. y Jackson, D. (2020). Family violence and COVID-19: Increased vulnerability and reduced options for support. International journal of mental health nursing, 29(4), 549-552. doi:10.1111/inm.12735

Westphal, J. D. y Khanna, P. (2003). Keeping Directors in Line: Social Distancing as a Control Mechanism in the Corporate Elite. Administrative Science Quarterly, 48(3), 361. doi:10.2307/3556678 


\section{(c) (1) ()(-)}

Esta obra está bajo una

Licencia Creative Commons Atribución-NoComercial-Compartirlgual 4.0 Internacional

Usted es libre de compartir o adaptar el material en cualquier medio o formato bajo las condiciones siguientes: (a) debe reconocer adecuadamente la autoría, proporcionar un enlace a la licencia e indicar si se han realizado cambios; (b) no puede utilizar el material para una finalidad comercial y (c) si remezcla, transforma o crea a partir del material, deberá difundir sus contribuciones bajo la misma licencia que el original.

Resumen de la licencia https://creativecommons.org/licenses/by-nc-sa/4.0/deed.es_ES

Texto completo de la licencia https://creativecommons.org/licenses/by-nc-sa/4.0/legalcode 